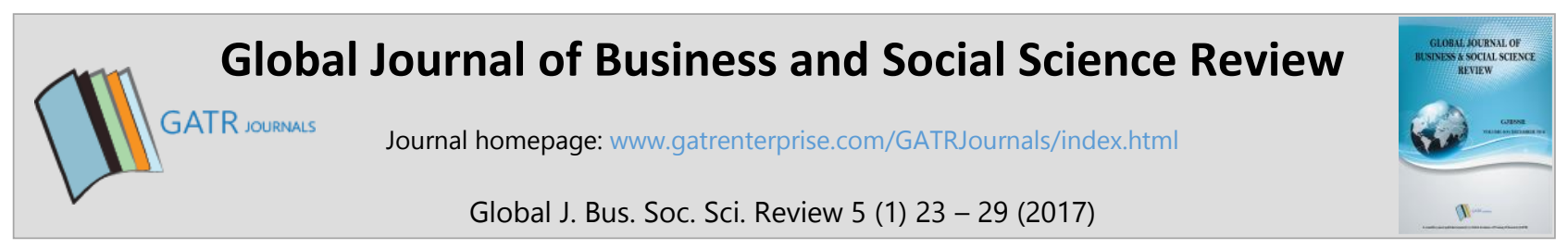

\title{
Dual Working Couples: Blessings or Burden
}

\author{
Raza Kamal ${ }^{1 *}$, Fizza Zehra ${ }^{2}$ and Shurooque Fatima ${ }^{3}$ \\ ${ }^{1}$ Assistant Professor, College of Management Sciences, PAF- Karachi Institute of Economics and Technology. Korangi Creek, \\ Karachi. Pakistan. \\ ${ }^{2}$ MBA Student, College of Management Sciences ,PAF- Karachi Institute of Economics and Technology, PAF-Karachi Institute of \\ Economics and Technology, Korangi Creek, Karachi 75190, Pakistan. \\ ${ }^{3}$ BBA Student, College of Management Sciences, PAF- Karachi Institute of Economics and Technology, PAF-Karachi Institute of \\ Economics and Technology, Korangi Creek, Karachi 75190, Pakistan.
}

\begin{abstract}
Objective - To examine the problems of dual working couples in the Pakistani context, examining their problems and suggesting measures to be taken by organizations to minimize their ill-effects on family structures and the organizations. Methodology/Technique - There were two different questionnaires designed for HR managers and working couples, the respondents for this study.

Findings - The findings support the belief that social factors stand out as the main reason for minimal participation of working couples in productive activities. The female gender still attributes a higher priority to family life and do not pursue professional career after the mid-career stage. National participation of educated females, especially in the urban centres will remain stagnant if affirmative action plans are not designed to encourage dual working couples to remain productive.

Novelty - Employers need to tailor their policies according to the preferences of couples in order to retain their skilled employees and obtain productive output from them. Joint family living is presently solving the problems being encountered by dual working couples, but it is fast fading in cities.
\end{abstract}

Type of Paper: Empirical.

Keywords: Adverse Working Conditions; Affirmative Action Plan; Benefits; Dual Working Couples; Flexible WorkHours; Pakistani Workforce; Telecommuting.

JEL Classification: J21, J24.

\section{Introduction}

Dual-family careers are an imperative in today's work style to give impetus to growth in productivity. This concept stresses that both family members pursue careers and at the same time maintain a harmonious family life together (Rapoport, 1971). By the year 2000, the proportion of married couples in which both partners

\footnotetext{
* Paper Info: Revised: September, 2016

Accepted: January, 2017

* Corresponding author:

E-mail: raza@pafkiet.edu.pk

Affiliation: College of Management Sciences, PAF- Karachi Institute of Economics and Technology.

Pakistan.
} 
worked full time had increased from $53.2 \%$ to $64.2 \%$ (U. S. Bureau of Labor Statistics, 2000). Canadian Press reported that the percentage of dual-income Canadian families nearly doubled in 40 years. In 2015, it has nearly exceeded $69 \%$ as compared to 1976 when it was reportedly only $36 \%$ (Stats show that $69 \%$ of households were dual income households in 2015 and 2016).

Pakistan, with a population exceeding 190 million, has only 12.5 million women in the work force. Between 2001 and 2002 approximately $1.9 \%$ of women were in managerial positions which has since declined to $1.6 \%$ between 2012 and 2013 (Hafeez, 2016). In the sub-continent, the most qualified and career oriented women are pushed to choose between career or family in the first few years of their marital life; they usually favor family responsibility (Buddhapriya, 2009). This problem is more pertinent in the urban sector where female representation in the work force is restricted only to 4\% (Abbasi, 2012). This scarce representation is attributed to male domination of the work environment (Buddhapriya, 2009), social and cultural taboos (Pearlin, 1985) as well as lack of support from the organizations (Kamal, 2015).

To examine the problems of dual working couples in the Pakistani context, this study will identify the problems and suggest measures to be taken by organizations to minimize their ill-effects on family structures and organizations.

\section{Literature Review}

Most researchers have identified that the rise of dual-career lifestyles has led to a lifestyle full of stressrelated family problems and stress in professional life (Pearlin, 1985). Desimmone, 2011 points out that the challenges faced by these couples are supported by the increasing role and rights of women in society and the changing perception of family values. The pressure to be a dual working couple is not only an economic compulsion but also a social imperative in most developing countries (Buddhapriya, 2009). This concept may have commenced as an imitation of western working philosophy but no more. With the high incidence of women entering the workforce and the changing perception of lifestyle in the millennial generation, it is important that national and organizational policies be tailored according to the preferences of the employees (Baral \& Bhargava, 2011).

The findings of recent studies on dual working couples are summarized as follows: Rosalind 2001 determined a few testable principles that advocate a healthy change in life of dual career couples. A few important parameters examined were buffering ( endency to offset a failure by success in another area), improvement in self confidence and self efficacy, added security of income in times of recession and layoffs and flexibility in the development of competencies (Rosalind chait Barnett, 2001). However, Buddhapriya 2009 points out that in India, family obligations reigns supreme and women are ready to sacrifice their career dreams for a harmonious family life. The study agrees that more control over work schedules, gender sensitive policies within organisations and increased support by spouses were desired by couples. Another study conducted by Catsouphes in 2007 in the USA titled 'Nurturing Family Studies' concluded that there are two goals that firms should aim to achieve; promoting business effectiveness and supporting employee's well being at home. They argued that if stress is not quarantined at work it is likely to spill over into other roles. The study further stresses that organizations should offer social support in the shape of dependent care services to alleviate related problems (Catsouphes, 2007). A more objective study carried out by Baral and Bhargava in 2011 identifies Work Life Benefits and Programs (WLBPs) implemented by some organizations in India. These programs have influenced the development of laws related to women such as maternity leave entitlements and work schedule or other benefits focused on family friendly policies. The study focuses on moderators that would change attitudes and behavior of employees leading to the minimization of work-life conflicts. It also identifies that these programs are more inclined to be implemented by organizations where the proportion of women employees is higher, for example in technology related firms. Another study highlights measures taken by leading companies to encourage options such as services in the same organization (Dudovskiy, 2012), job sharing (Wood, 2009) and telecommuting (Torrington, 2008). It would be worthwhile 
to examine if these changes in policies are in fact based on sensitivity towards the problems of women employees or re simply a cost cutting measure (Milkovitch, 1976).

\subsection{Strong Responsibilities to Family Obligations}

Working women have dual responsibilities towards their work but also towards their families. In developing countries, women are more committed to their families than their careers (Buddhapriya, 2009), This commitment takes precedence due to a lack of supporting policies within their employment such as the absence of flexi-time arrangements or telecommunication abilities (Greenhaus, 2000), discriminatory promotion policies and overloads of physical effort. On the other hand, there is a lack of encouragement by extended family members (Buddhapriya, 2009), insufficient help from spouses (Greenhaus, 2000) and associated guilt of not being able to give quality time to their children (Lloyd, 2006). A study carried out in 1990 (Hendrix, 1994) and later in 2000 points out that males devote approximately 10 to 15 hours less per week as compared to their spouses towards household chores, thereby adding to the workload and sources of stress of women (Greenhaus, 2000). Keeping in mind the above argument, the hypothesis of this study is framed as follows; South Asian women give more priority to family obligations as compared to professional work.

\subsection{Stress Overload}

According to a survey conducted by Alcorn, 2011, 43\% of working parents struggle with depression, whereas $80 \%$ catch up on work nights and weekends and $88 \%$ have stated that they have suffered from at least one stress related health problems since becoming a working parent. This physical burnout is as a result of illbalanced work-life patterns, extensive role conflicts leading to exhaustion, absenteeism from work, productivity loss and strained companionship (Aryee, 2005).

\subsection{Infrastructure Support}

A significant difference lies between the work and household environment between the developed and less developed regions (Baral \& Bhargava, 2011). The infrastructure of developed countries is supported by an elaborate infrastructure of transportation, utilities and community support which is absent in the developing countries (Hyde, 2011; Buddhapriya, 2009). In view of this disparity it is hypothesized that there is lack of infrastructure support in Pakistan thereby increasing inconvenience and stress on dual working couples.

\subsection{Joint Family Support}

In the sub-continent, dual working couples are aided by the joint family living style which is mostly absent in the western world (Buddhapriya, 2009). This extended family living, though very convenient for child rearing and household chores, is sometimes a double edged dilemma due to rising expectations by in-laws, living under conditions of compromises and occasional outbursts by family members (Aryee, 2005). Though two career members enhance the economic wellbeing of a family, they also require adroit handling of work and family obligations by the couple. A cooperative and an empathetic attitude displayed by extended family members and a family friendly policy designed by the employer in shape of flexible working hours, telecommuting and the availability of child care centres would appease the dissatisfied couples (Rajadhyaksha \& Bhatnagar, 2000).

\section{Methodology of Research}

The reviewed literature on the subject is in the infant stage, lacking clarity and concrete proactive measures to substantiate a meaningful interpretation, particularly in relation to developing countries; therefore there is a real need for further research. This research is more qualitative in nature; with "work-life balance" as the independent variable and "dual working couples" as the dependent variable and the introduction of flex- 
timings, telecommunication and child-care centres as the moderating factors. There are two actors identified as stakeholders to this issue who would be consulted to settle the dichotomy. All respondents were from Karachi (metropolitan city). A total of 71 respondents representing dual working couples from the banking and service industry (high growth areas) were administered the questionnaire and 29 human resource (HR) executives representing organizational management were chosen for this study. Later, a separate focus group discussion was conducted with both groups. It is presumed that the opinion of both these categories could help reduce the gulf that exists today.

Two separate structured questionnaires were prepared for both categories of respondents. The rationale of the questionnaire and the type of questions is as detailed below.

\subsection{Working Couples}

There was a total of 7 closed ended questions related to the characteristics profile of the respondents such as gender, industrial sector, work experience, marriage tenure, family structure (independent or joint), remuneration range and the number of children. These facts were considered important to ascertain whether opinions differed between the respondents based on these parameters. The items related to the research question were segregated into work- life conflict, physical/physiological impact of work on life, benefits in vogue and desired preferences related to jobs, support from spouse and problems related to child grooming.

\subsection{HR Managers}

These participants represented different industries such as IT, health care, textile, pharmaceutical, banking, shipping and education. $80 \%$ of these participants were male executives. It can be concluded that the sample is moderately represented to reflect the population. A total of 3 closed questions related to characteristics of the firm such as the industrial sector, number of employees by gender at different hierarchical levels and number of dual working couples were included in the instrument. The items related to the topic focused on the type of benefits offered to working couples, problems encountered by organizations for this category of employment and perception of other employees if additional benefits are offered to dual working couples.

\subsection{Respective Profiles}

Of the 71 participants who were dual working couples, only 2 were from the government sector and the remaining 69 belonged to the private sector. About $90 \%$ of the respondents represented the banking sector while $10 \%$ were affiliated with health care services. In terms of managerial hierarchy, about $33 \%$ were senior managers, $20 \%$ assistant managers, $22 \%$ supervisory staff and $24 \%$ were entry level employees. The majority of respondents were male (53\%) with a married life of up to 5 years. $44 \%$ of the respondents had their children under the age of 5 years. About $34 \%$ of the respondents had a marriage exceeding 10 years. Most of the respondents (about 60\%) are living in joint family systems and the remaining respondents lived independently. The profile of the sample is moderately related to the population.

\section{Discussion}

\subsection{General Findings}

The sample consisted of 71 working couples and 29 HR managers. The questionnaire was well received and reflected by prompt responses. However, there were a few items where ambiguous responses were received. The male respondents were about $15 \%$ more than the females. $61 \%$ of the respondents were living in joint family systems which took care of problems like household chores and child grooming. The HR managers however agreed that additional benefits are warranted for dual working couples but were also of view that it could lead to resentment amongst other employees. 
Although dual working couples are a prominent life style choice of the $21^{\text {st }}$ century, according to the perception of the surveyed HR managers of Pakistan, women are still not part of this reality. Table 1 reflects the same findings as by (Abbasi, 2012; Baral \& Bhargava, 2011; Buddhapriya, 2009). They also show that approximately $48 \%$ employees could be categorized as dual working couples in their organizations, not necessarily in the same organization.

Table 1: Composition of Women at Different Hierarchical Levels

\begin{tabular}{|l|l|l|l|l|l|l|l|}
\hline \multicolumn{2}{|l|}{ Top Management } & \multicolumn{2}{l|}{ Middle Management } & \multicolumn{2}{l|}{ First Executive } & \multicolumn{2}{l|}{ Worker Level } \\
\hline Male & Female & Male & Female & Male & Female & Male & Female \\
\hline $90 \%$ & $10 \%$ & $83 \%$ & $17 \%$ & $75 \%$ & $25 \%$ & $75 \%$ & $25 \%$ \\
\hline
\end{tabular}

One reason behind the lower number of females is the stereotype perception persisting in our society that females are more of a home-maker rather than a professional worker. However, this trend is fast changing as is also reflected by the data in Table $1.48 \%$ of HR managers thought that financial consideration is the main reason for employment, however the working couples (46\%) termed it as professional outlook amongst spouses for choosing employment. This finding substantiates hypothesis 1 and is in line with most of the quoted citations. For this figure to be substantial, there is a dire need of initiating an affirmative action plan at the national level.

\subsection{Source of work-life Conflict}

Although the source of conflict amongst dual working couples was not the primary objective of this study, it did emerge as a moderating factor. Work related practices by organizations do not necessarily influence employee work-life conflicts but do mitigate them since exhaustion, work stress and overload of household chores may turn out to be catalysts for frequent quarrels (Glass, 1998).

\subsection{Benefits Desired By Dual Couples}

The HR managers agreed that the companies do not consider this class of employees as a distinct category and therefore have not been addressing their issues. The benefits desired in order of priority were; flexible time arrangements, extra leave quotas, telecommuting and child care centre availability. HR managers agreed with flexi-time and child care centre availability but did not share the same views on extra leave quotas or telecommuting. There is little difference in the opinion of the respondents on the basis of work experience, marriage span or the number of children however the preferences become more prominent at lower levels of management, on flexi-time arrangements and extra leave quotas, as service and marriage span increases (Table 2). Telecommuting did not figure out in their preferences, despite being a very popular option in developed societies, probably due to a lack of infrastructure support (Dudovskiy, 2012). Affirmative Action Plans by industries for dual working couples would help mitigate the problems of dual working couples and improve retention, absenteeism and commitment towards organizations.

Table 2: Demographic Differences on Benefits

\begin{tabular}{|l|l|l|l|l|}
\hline Factors & benefits & $<\mathbf{5}$ years & $\mathbf{5 - 1 0}$ years & $>10$ years \\
\hline Based on experience & Flexible timings & 50 & 41.3 & 58.3 \\
& Extra leave quota & 27.7 & 51.7 & 29.1 \\
& Child care centre & 5.5 & 6.9 & 4.1 \\
& Telecommuting & 16.6 & 3.4 & 8.3 \\
\hline Marriage span & Flexible timings & 40 & 50 & 66.6 \\
& Extra leave quota & 40 & 41.6 & 29.2 \\
\hline
\end{tabular}




\begin{tabular}{|l|l|l|l|l|}
\hline & Child care centre & 5.7 & 8.3 & 4.2 \\
& Telecommuting & 14.3 & 0 & 0 \\
\hline Age of children & Flexible timings & 42.1 & 46.1 & 70 \\
& Extra leave quota & 39.5 & 46.1 & 25 \\
& Child care centre & 5.2 & 7.6 & 5 \\
& Telecommuting & 13.1 & 0 & 0 \\
\hline
\end{tabular}

\subsection{Additional Benefits for dual working couples}

Around 58\% of the HR executives responded that couples should receive additional benefits as it will enhance their performance at work and job satisfaction as they would be able to devote quality time with their families. $42 \%$ of the HR managers felt that additional benefits to dual working couples could lead to resentment or discrimination amongst rest of the employees and were in favor of the status quo.

Home chores are usually neglected or performed by servants or in the case of a joint family, by the other family members. $46 \%$ of respondents expressed an opinion that spouses usually helped in some form or another, but the tedious tasks are mostly performed by the women. It takes most of their discretionary time and adds to their exhaustion. This point requires mutual understanding between the partners. Social taboos like husbands reluctantly helping in household matters is fast disappearing amongst millennials.

$61 \%$ of the respondents expressed that living in a joint family system facilitates child care and gives them mental peace that their children are being taken care of by their parents/in laws (Buddhapriya, 2009; Baral \& Bhargava, 2011; Rajadhyaksha \& Bhatnagar, 2000). 70\% of couples with moderate earnings expressed that that a joint family system also allows them to educate their children in better institutions. However, $25 \%$ of respondents who lived independently opted for child care centres to lower their level of stress.

$65 \%$ of the respondents felt that working in the same organizations is not a great idea; reasons quoted ranged from backfire repercussions, infringement on independence and incompatibility in professions. Similarly 58\% of HR managers are also apprehensive of this mechanism quoting privacy infringements, placement problems and internal squabbling.

\section{Conclusion}

Dual working couples need to balance their work and home responsibilities to bring harmony in their lives. Employers need to tailor their policies according to the preferences of couples in order to retain their skilled employees and obtain productive output from them. Joint family living is presently solving the problems being encountered by dual working couples, but it is fast fading in many cities. Organizations that recognise these facts, and are willing to experiment with new work schedules, are likely to nip the problem in the bud.

The findings of this research are not complete in form and require further investigations in order to crystallize the effect of the measures adopted by firms in terms of control on absenteeism, increasing efficiency of dual working couples at work and at home and the impact of social exchange to provide them support from the community.

\section{References}

Abbasi, S. (2012, Jul 29). Need for Affirmative Action- Interview with Younis Khalid Director Aurat Fouindation. $D A W N$.

Alcorn, K. (2011, online). Survey: 88\% of Working Parents Suffer Stress Related Health Problems. Retrieved Jul 26, 2016, from Customfitworkplan.org/section/blog-categories/dualcouple career.

Aryee, S. E. (2005). Rhythms of Life: Antececedents and Outcome of Work-Family Balance In Employed Parents. Journal of Applied Psychology 90(1), 132-146. 
Buddhapriya, S. (2009). Work Family Balances issue and their impact on Career Decisions: A study of Indian Women preferences. VIKALPA, The Journal for Decision Makers, 14.

Buddhapriya, S. (2009). Work Life Barriers Issues and Impact on career Decisions: A study of Indian Women Preferences. Vikdpa, The Journal For Decision makers, 31-46.

Catsouphes, M. C. (2007). HRD Responses to Work-Life Stressors. Toronto.

Desimmone, J. W. (2011). Human Resource Development 6 ed. South -Western College, Canada.

Dudovskiy, J. (2012, Jul 20). Work Life balance Issues for Dual Career Couples. Retrieved July 25, 2016, from Research methodology: Http://www.research methodology.

Glass, J. R. (1998). Family Responsive Policies and Employee Retention. Social Forces 76(4), 1401-1435.

Greenhaus, S. F. (2000). Work and Family-Allies or Enemies. London UK: Oxford.

Hafeez, E. (2016). Society nipped in the bud. DAWN.

Hendrix. (1994). Orgnizational and Extraorganizational Factors affecting Stress Employees Wellbeing and Absenteeism for Males and Females. Journal of Business and Psychology 9(2), 103-128.

Hyde, R. C. (Oct 2011). Women, Men, Work and Family. American Psychologist.

Kamal, R. (2015). Human Resorce Management in the Industries of Pakistan. Karachi: Higher Education Commission of Pakistan.

Lloyd, B. L. (2006). Human Resource Management, eighth Edition . McGraw Hill/Irwin.

Pearlin, L. (1985). The Structure of Coping. Journal of Health and Social Behavior No 19, 2-21.

Baral, R., \& Bhargava, S. (2011). HR interventions for work-life balance: evidences from organisations in India. International Journal of Business, Management and Social Sciences, 2(1), 33-42.

Rapoport, R. a. (1971). Further Considerations on the Dual Career Families. Human Relation, 24(6).

Rosalind chait Barnett, J. S. ( 2001). Women, Men, Work and Family: An expansionist Theory. American Psychologist, 56(10), 781-796.

Stats show that $69 \%$ were dual income household in 2015. (2016). Financial Post.

Torrington, D. H. (2008). Human Resource Management. Pearson Education.

U. S. Bureau of Labor Statistics). (2000).

Rajadhyaksha, U., \& Bhatnagar, D. (2000). Life role salience: A study of dual-career couples in the Indian context. Human Relations, 53(4), 489-511.

Wood, G. (2009). Human Resource Management A Critical Approach. Taylor \& Francis. 